\title{
ECT-001 Expanded Cord Blood
}

National Cancer Institute

\section{Source}

National Cancer Institute. ECT-001 Expanded Cord Blood. NCI Thesaurus. Code C156693.

A preparation of umbilical cord blood (UCB) co-cultured and expanded in an optimized culture system with a small molecule agonist of hematopoietic stem cell (HSC) renewal, with potential use in hematopoietic cell transplantation (HCT). Upon administration, the ECT-001 expanded cord blood cells increase and restore the number of hematopoietic stem and progenitor cells (HSPCs) that can differentiate into a variety of cell types and promote blood cell recovery. Compared to untreated UBCs, ECT-001 expanded UCB cells may exhibit enhanced stem cell proliferation and engraftment. 